\title{
Reassignment of the Intermediate Strains of Proteus rettgeri biovar 5 to Providencia stuartii on the Basis of the Somatic $(\mathrm{O})$ Antigens
}

\author{
JOHN L. PENNER AND JOAN N. HENNESSY \\ Department of Medical Microbiology, Faculty of Medicine, University of Toronto, and Department of \\ Microbiology, Toronto General Hospital, Toronto, Ontario, Canada
}

\begin{abstract}
The 181 bacteria classified as Proteus rettgeri biovar 5 considered to be a group intermediate to $P$. rettgeri and Providencia stuartii were found, in all cases, to possess O-specificities characteristic of Providencia O-serovars. Isolates of the intermediate group showed biochemical reactions characteristic of Prov. stuartii except for positive reactions in tests for urea hydrolysis. The reassignment of the intermediate strains ( $P$. rettgeri biovar 5 ) to Prov. stuartii is advocated.
\end{abstract}

An intermediate group of bacteria possessing characteristics of both Providencia stuartii and Proteus rettgeri have been described and assigned to a newly proposed biovar for $P$. rettgeri (3). Recent epidemiological investigations have revealed that some of these intermediates were isolated along with Prov. stuartii from patients cross-infected in the same institution (7). The intermediate strains differed from the Prov. stuartii in positive reactions for urea hydrolysis but reacted identically in 17 other biochemical tests and possessed O-specificities characteristic of Providencia. The interpretation was therefore made that the intermediate strains were urease-positive variants of a Prov. stuartii endemic strain, and it became evident that it would be more appropriate to allocate these particular intermediates to Prov. stuartii rather than to $P$. rettgeri. Furthermore, 14 isolates that were, except for urease-positive reactions, biochemically similar to Proteus inconstans biovar B (Prov. stuartii) were considered by Ursing to be urease-positive variants of this species rather than $P$. rettgeri (8).

In the present study, the $\mathrm{O}$ antigenic structures of the intermediates in our collection now classified as $P$. rettgeri biovar 5 were reexamined for relationships to the $P$. rettgeri included in the other biovars and to the Prov. stuartii to determine to which species they were most closely related and with which they should be classified.

\section{MATERIALS AND METHODS}

Bacterial isolates. $P$. rettgeri and Prov. stuartii isolates were obtained, with a few exceptions, from the urine of patients in hospitals in Canada and the United States.

Biochemical and serological tests. Procedures for determining biochemical reactions have been de- scribed in detail $(1,3)$. Christensen medium (Difco) was used in tests for urease activity. Tests were read at $24 \mathrm{~h}$, and positive tests were recorded on observation of a pink color on the agar surface. Serotyping of $P$. rettgeri was performed on the basis of the $O$ antigens previously described (5) and by methods recently reported (4). Providencia were serotyped on the basis of $\mathrm{O}$ antigens by the scheme reconstituted in our laboratory (6) from the one proposed earlier by Ewing et al. (2).

\section{RESULTS}

Typing intermediates in $P$. rettgeri $O$ antisera. Cell suspensions of each of the 181 isolates in our collection assigned to the intermediate group of $P$. rettgeri biovar 5 (Table 1) were tested in $P$. rettgeri $\mathrm{O}$ antisera. The results are shown in Table 2. Only seven isolates, all from one hospital, did not agglutinate in any of the 84 antisera. Among the 174 isolates that were typable, a total of nine O-serovars were recognized.

Relations to Providencia of the $\mathrm{O}$-serovars among $P$. rettgeri biovar 5 isolates. Antigen preparations of the strains from the serotyping scheme for $P$. rettgeri that were homologous for antisera that agglutinated biovar 5 isolates were each tested in the 63 Providencia $\mathrm{O}$ antisera. Except for $P$. rettgeri O82, each antigen preparation was agglutinated in either one or two Providencia antisera (Table 3). Cross-absorption and cross-titration experiments were performed between the $P$. rettgeri and the corresponding Providencia antisera. Between some pairs an "a,b-a,c" relation was identified and, between others, a test of identity was demonstrated. Tests of identity were shown to occur between Providencia and those O-serovars of $P$. rettgeri (O83 and $\mathrm{O} 84$ ) that belonged to $P$. rettgeri biovar 5. Except for one other test of iden- 
TABLE 1. Biochemical reactions of Proteus rettgeri and Providencia stuartii ${ }^{a}$

\begin{tabular}{|c|c|c|c|c|c|c|}
\hline \multirow{2}{*}{ Substrate- } & \multicolumn{5}{|c|}{$P$. rettgeri biovars } & \multirow{2}{*}{$\begin{array}{c}\text { Prov. } \\
\text { stuartii }\end{array}$} \\
\hline & 1 & 2 & 3 & 4 & 5 & \\
\hline Urea & + & + & + & + & + & - \\
\hline Trehalose & - & - & - & + or - & + & + \\
\hline Mannitol & + & + & + & + & + or - & -+ or - \\
\hline Salicin & + & + & - & - & - & - \\
\hline Rhamnose & - & + &.+ & - & - & - \\
\hline Adonitol & + & + & + & + & - & + or - \\
\hline Arabitol & + & + & + & + & - & - \\
\hline Erythritol & or - & + or - & + or & + or - & - & - \\
\hline
\end{tabular}

a All members show positive reactions for phenylalanine deaminase and acid production in inositol.

TABLE 2. Results of serotyping $181 P$. rettgeri biovar 5 isolates in $P$. rettgeri $O$ antisera

\begin{tabular}{ccc}
\hline$P$. rettgeri O-serovar & No. of isolates & No. of sources \\
\hline 6 & 1 & 1 \\
10 & 8 & 2 \\
12 & 4 & 3 \\
26 & 75 & 3 \\
42 & 62 & 3 \\
64,80 & 6 & 1 \\
$82^{a}$ & & \\
83 & 9 & 2 \\
84 & 9 & 3 \\
Untypable & 7 & 1 \\
\hline
\end{tabular}

${ }^{a} \mathrm{O}$-serovar 82 is included because it is a biovar 5 strain, although $\mathrm{O}$ antiserum 82 did not agglutinate other $P$. rettgeri isolates.

TABlE 3. O-antigenic relations between crossreacting $P$. rettgeri and Providencia 0 -serovars

\begin{tabular}{|c|c|c|}
\hline \multicolumn{2}{|c|}{ Serotyping strains } & \multirow{2}{*}{ Relation } \\
\hline P. rettgeri & Providencia & \\
\hline 6 & 9 & $a, b-a, c$ \\
\hline 10 & 63 & $a, b-a, c$ \\
\hline 12 & 44 & $a, b-a, c$ \\
\hline 26 & 17 & Unilateral $^{\alpha}$ \\
\hline 42 & 4 & $\mathrm{a}, \mathrm{b}-\mathrm{a}, \mathrm{c}^{a}$ \\
\hline 42 & 52 & Identity $^{a}$ \\
\hline 64 & 25 & $a, b-a, c$ \\
\hline 80 & 25 & $a, b-a, c$ \\
\hline 83 & 24 & Identity \\
\hline 84 & 56 & Identity \\
\hline
\end{tabular}

a Demonstrated in an earlier study (7).

tity between $P$. rettgeri $\mathrm{O} 42$ and Providencia $\mathrm{O} 52$, and the unilateral relation between $P$. rettgeri $\mathrm{O} 26$ and Providencia $\mathrm{O} 17$ previously reported (7), all other cross-reactants were related through an "a,b-a,c" relation.

Specificities of the $O$ antigens of isolates that agglutinated in both $P$. rettgeri and Providencia $\mathrm{O}$ antisera. Isolates that were ag- glutinated by $P$. rettgeri and Providencia antisera against serotyping strains shown to be related through an "a,b-a,c" relation were further tested in cross-absorbed antisera. The effect of the cross-absorption was to remove antibody against the cross-reacting "a" component, leaving antibody directed against the $\mathrm{O}$-specificity.

One isolate of $P$. rettger $i$ biovar 5 and others of biovars 1, 2, and 3 agglutinated in unabsorbed $P$. rettgeri $\mathrm{O}$-antiserum 6 and in Providencia $\mathrm{O}$-antiserum 9 (Table 4). When retested in cross-absorbed antisera, it was observed that the biovar 5 isolate agglutinated in Providencia O-antiserum 9 absorbed with $P$. rettgeri O6, and the biovars 1,2 , and 3 isolates agglutinated in $P$. rettgeri $\mathrm{O}$-antiserum 6 absorbed with Providencia O9. From these results, it was concluded that isolates of biovars 1,2 , and 3 possessed O-specificities indistinguishable from the $P$. rettgeri $\mathrm{O} 6$ strain and the biovar 5 isolate possessed an O-specificity like that of the Providencia O9 strain. A similar conclusion was reached for isolates agglutinable in unabsorbed $P$. rettgeri $\mathrm{O}$-antiserum 12 and Providencia $\mathrm{O}$ antiserum 44 . Those of biovars 1,2 , and 3 agglutinated in $P$. rettgeri $\mathrm{O}$-antiserum $12 \mathrm{ab}$ sorbed with Providencia strain $\mathrm{O} 44$ and the biovar 5 isolates agglutinated in Providencia O-antiserum 44 absorbed with $P$. rettgeri strain 012.

The $P$. rettgeri $\mathrm{O} 10$ and Providencia $\mathrm{O} 63$ pair of antisera agglutinated isolates of Prov. stuar$t i i$ in addition to isolates of $P$. rettger $i$ biovars 2 , 3 , and 5 (Table 5). The isolates of biovars 2 and 3 , as in the cases above, identified with the $P$. rettgeri serovar, and those of biovar 5 and Prov. stuartii identified with the Providencia serovar.

Isolates of $P$. rettgeri biovar 5 and Prov. stuartii have been previously reported to agglutinate in unabsorbed $P$. rettgeri O-antiserum 26, in unabsorbed Providencia O-antiserum, 17 and in cross-absorbed $\mathrm{O}$-antiserum 17 (7). The only isolate of a different biovar was the $\mathrm{O} 26$ strain (biovar 1), and it agglutinated only in homologous antiserum.

The interrelationships among $P$. rettgeri O42, Providencia O52, and Providencia O4 were more complex. The first two were shown to be antigenically identical but both cross-reacted with the 04 strain on the basis of an "a" component common to all three $(6,7)$. $P$. rettgeri biovar 5 isolates from two hospitals agglutinated in Providencia O-antiserum 4 absorbed with $P$. rettgeri $\mathrm{O} 42$ (or Providencia O52), but biovar 5 isolates from a third hospital and one biovar 3 isolate agglutinated, like the $P$. rett- 
TABle 4. Reactions in $P$. rettgeri $O$ antiserum 6 and in Providencia $O$ antiserum $9^{a}$

\begin{tabular}{|c|c|c|c|c|}
\hline \multirow[b]{2}{*}{ Antigen } & \multicolumn{2}{|c|}{ Unabsorbed antisera } & \multicolumn{2}{|c|}{ Absorbed antisera ${ }^{\circ}$} \\
\hline & P. rettgeri $\mathrm{O} 6$ & Providencia $\mathrm{O} 9$ & $\begin{array}{c}\text { P. rettgeri O6 } \\
\text { (Providencia O9) }\end{array}$ & $\begin{array}{l}\text { Providencia } 09 \\
(P \text {. rettgeri } \mathrm{O} 6)\end{array}$ \\
\hline \multicolumn{5}{|l|}{ Serotyping strains } \\
\hline P. rettgeri $\mathrm{O} 6$ & $5,120^{r}$ & 640 & 1,280 & 0 \\
\hline Providencia 09 & 10,240 & 640 & 0 & 2,560 \\
\hline & & & & \\
\hline \multicolumn{5}{|l|}{$P$. rettgeri biovar: } \\
\hline 1 & $+d$ & + & + & - \\
\hline 2 & + & + & + & - \\
\hline 3 & + & + & + & - \\
\hline 5 & + & + & - & + \\
\hline
\end{tabular}

a Titrations were performed by passive hemagglutination. Initial dilution of antisera was 1:40. Negative results at this dilution are indicated by a zero; titers are expressed as reciprocals of the highest dilutions showing agglutination.

${ }^{b}$ Antisera were absorbed with the strains in parentheses.

" Numbers indicate titration results.

a Plus or minus indicates slide agglutination results.

TABle 5. Reactions in P. rettgeri $O$ antiserum 10 and in Providencia $O$ antiserum $63^{a}$

\begin{tabular}{|c|c|c|c|c|}
\hline \multirow[b]{2}{*}{ Antigen } & \multicolumn{2}{|c|}{ Unabsorbed antisera } & \multicolumn{2}{|c|}{ Absorbed antisera ${ }^{b}$} \\
\hline & P. rettgeri $\mathrm{O} 10$ & Providencia $\mathrm{O} 63$ & $\begin{array}{c}\text { P. rettgeri } 010 \\
\text { (Providencia O63) }\end{array}$ & $\begin{array}{l}\text { Providencia } 063 \\
(P \text {. rettgeri } \mathrm{O} 10)\end{array}$ \\
\hline \multicolumn{5}{|l|}{ Serotyping strains } \\
\hline$P$. rettgeri $\mathrm{O} 10$ & $10,240^{c}$ & 5,120 & 2,560 & 0 \\
\hline Providencia $\mathrm{O} 63$ & 2,560 & 10,240 & 0 & 2,560 \\
\hline \multicolumn{5}{|l|}{ Isolates } \\
\hline \multicolumn{5}{|l|}{ P. rettgeri biovar: } \\
\hline 2 & $+d$ & + & + & - \\
\hline 3 & + & + & + & - \\
\hline 5 & + & + & - & + \\
\hline Prov. stuartii & + & + & - & + \\
\hline
\end{tabular}

${ }^{a}$ Titrations were performed by passive hemagglutination. Initial dilution of antisera was 1:40. Negative results at this dilution are indicated by a zero; titers are expressed as reciprocals of the highest dilutions showing agglutination.

${ }^{b}$ Antisera were absorbed with the strains in parentheses.

c Numbers indicate titration results.

${ }^{d}$ Plus or minus indicates slide agglutination results.

geri $\mathrm{O} 42$ strain, in both $P$. rettgeri $\mathrm{O} 42$ and Providencia $\mathrm{O52}$ antisera after absorption with Providencia $\mathrm{O} 4$ strain.

Isolates that agglutinated in both $P$. rettgeri $O$ antisera 64 and 80 were noted previously (4). No cross-reacting component was evident between these serovars and it was interesting, therefore, to find in the present study that both strains agglutinated in Providencia O-antiserum 25. Evidence was obtained that the $\mathrm{O} 25$ strain bears two cross-reacting componentsone in common with the $P$. rettgeri $\mathrm{O} 64$ and the other in common with O80 (Table 6). The biovar 5 isolates reacted in a fashion identical to Prov. stuartii isolates typed as Providencia $\mathrm{O} 25$, and the one biovar 2 isolated reacted like the $P$. rettgeri $\mathrm{O} 80$ strain.

$P$. rettgeri serovars 083 and O84, both biovar 5 strains, showed tests of antigenic identity with Providencia O-serovars 24 and 56, respectively. Antisera against these did not agglutinate $P$. rettgeri of biovars 1 to 4 in our collection.

$P$. rettgeri serovar 082. $P$. rettgeri $\mathrm{O} 82$ antiserum did not agglutinate $P$. rettgeri isolates of biovars 1 to 4 but did agglutinate two Prov. stuartii isolates untypable in the 63 Providencia $\mathrm{O}$ antisera and, hence, it would appear appropriate to include this $\mathrm{O}$-specificity with the Providencia. 
TABLE 6. Reactions in P. rettgeri $O$ antisera 64 and 80 and in Providencia $O$ antiserum $25^{a}$

\begin{tabular}{|c|c|c|c|c|c|c|c|}
\hline \multirow[b]{2}{*}{ Antigen } & \multicolumn{3}{|c|}{ Unabsorbed antisera } & \multicolumn{4}{|c|}{ Absorbed antisera $^{b}$} \\
\hline & $\begin{array}{l}P . \text { rettgeri } \\
\text { O64 }\end{array}$ & $\begin{array}{l}P . \text { rettgeri } \\
080\end{array}$ & $\begin{array}{l}\text { Providencia } \\
\text { O25 }\end{array}$ & $\begin{array}{c}\text { P. rettgeri } \\
\text { O64 } \\
\text { (Providencia } \\
\text { O25) }\end{array}$ & $\begin{array}{c}\text { P. rettgeri } \\
\text { O80 } \\
\text { (Providencia } \\
\text { O25) }\end{array}$ & $\begin{array}{c}\text { Providencia } \\
\text { O25 } \\
(P . \text { rettgeri } \\
\text { O64) }\end{array}$ & $\begin{array}{l}\text { Providencia } \\
\text { O25 } \\
\text { (P. rettgeri } \\
\text { O80) }\end{array}$ \\
\hline \multicolumn{8}{|l|}{$\begin{array}{r}\text { Serotyping } \\
\text { strains }\end{array}$} \\
\hline$P$. rettgeri $\mathrm{O} 64$ & $10,240^{r}$ & 0 & 1,280 & 5,120 & 0 & 0 & 640 \\
\hline P. rettgeri 080 & & 5,120 & 640 & 0 & 5,120 & 320 & 0 \\
\hline Providencia $\mathrm{O} 25$ & 2,560 & 1,280 & 5,120 & 0 & 0 & 1,280 & 2,560 \\
\hline \multicolumn{8}{|l|}{ Isolates } \\
\hline \multicolumn{8}{|l|}{$P . \quad$ rettgeri } \\
\hline 2 & $-d$ & + & + & - & + & + & - \\
\hline 5 & + & + & + & - & - & + & + \\
\hline Prov. stuartii & + & + & + & - & - & + & + \\
\hline
\end{tabular}

a Titrations were performed by passive hemagglutination. Initial dilution of antisera was 1:40. Negative results at this dilution are indicated by a zero; titers are expressed as reciprocals of the highest dilutions showing agglutination.

${ }^{b}$ Antisera were absorbed with the strains in parentheses.

- Numbers indicate titration results.

a Plus or minus indicates slide agglutination results.

O-specificities of intermediates untypable in $P$. rettgeri antisera. The seven $P$. rettgeri biovar 5 isolates that were untypable in $P$. rettgeri $\mathrm{O}$ antisera were agglutinated in Providencia $\mathrm{O} 55$ antiserum. Therefore, like all others of this intermediate group, they possessed O-specificities characteristic of a Providencia O-serovar.

\section{DISCUSSION}

A group of bacteria considered intermediate between Prov. stuartii and $P$. rettgeri were assigned to $P$. rettgeri biovar 5 because they showed urease activity and because their exact position in reference to Prov. stuartii was not known (3). The results of the present study have shown that all biovar 5 isolates in our collection have $\mathrm{O}$-specificities characteristic of Providencia strains. Agglutination in P. rettgeri antisera was attributable to antibody directed against either cross-reacting components or against $\mathrm{O}$-specificities of $P$. rettgeri that were serologically indistinguishable from those of Providencia O-serovars.

It was also apparent from biochemical studies that these intermediate bacteria, except for their reaction in urea, were like the Prov. stuartii $(3,7,8)$. Hence, support for maintaining the $P$. rettgeri biovar 5 subdivision is based on the positive reactions of these bacteria in urea, a characteristics of the genus Proteus. This allows a single biochemical test to be a criterion sufficient to separate otherwise identical bacteria into two genera. Consideration should therefore be given to a reassignment to
Prov. stuartii of the bacteria now included in biovar 5 of $P$. rettgeri.

\section{ACKNOWLEDGMENT}

This work was supported by the Medical Research Council (Canada) Grant no. MA-5648.

\section{REPRINT REQUESTS}

Address reprint requests to: Dr. John L. Penner, Department of Medical Microbiology, Banting Institute, $100 \mathrm{Col}$ lege St., Toronto, Canada, M5G 1 L5.

\section{LITERATURE CITED}

1. Ewing, W. H. 1962. The tribe Proteeae: its nomenclature and taxonomy. Int. Bull. Bacteriol. Nomen. Taxon. 12:93-102.

2. Ewing, W. H., K. E. Tanner, and D. A. Dennard. 1954. The Providence group: an intermediate group of enteric bacteria. J. Infect. Dis. 94:134-140.

3. Penner, J. L., N. A. Hinton, and J. Hennessy. 1975. Biotypes of Proteus rettgeri. J. Clin. Microbiol. 1:136142.

4. Penner, J. L., N. A. Hinton, and J. N. Hennessy. 1976. Evaluation of a Proteus rettgeri O-serotyping system for epidemiological investigation. J. Clin. Microbiol. 3:385-389.

5. Penner, J. L., N. A. Hinton, and J. Hennessy. 1974. Serotyping of Proteus rettgeri on the basis of $\mathrm{O}$ antigens. Can. J. Microbiol. 20:777-789.

6. Penner, J. L., N. A. Hinton, J. N. Hennessy, and G. R. Whiteley. 1976. Reconstitution of the somatic (O-) antigenic scheme for Providencia and preparation of O-typing antisera. J. Infect. Dis. 133:283-292.

7. Penner, J. L., N. A. Hinton, G. R. Whiteley, and J. N. Hennessy. 1976. Variation in urease activity of endemic hospital strains of Proteus rettgeri and Providencia stuartii. J. Infect. Dis. 134:370-376.

8. Ursing, J. 1974. Biochemical study of Proteus inconstans (Providencia). Occurrence of urease positive strains. Acta Pathol. Microbiol. Scand. Sect. B. 82:527-532. 